\title{
Pyrophosphate arthropathy in the carpal and metacarpophalangeal joints
}

\author{
M. BOURQUI, T. L. VISCHER, P. STASSE, C. DOCQUIER, AND \\ G. H. FALLET
}

From the Division of Rheumatology, University Department of Medicine, Hôpital Cantonal Universitaire, Geneva, Switzerland

SUMMARY The hand $x$-rays of a group of patients with generalised osteoarthrosis alone were compared with those of patients with generalised osteoarthrosis and chondrocalcinosis (CC). An arthropathy seemingly specific for CC could be identified in the metacarpophalangeal (MCP) and carpal joints. In the MCP joints it was characterised by subchondral rarefactions, deviation of the joint axis, joint space narrowing, and osteophytosis. Usually only the second and/or third MCP joints are affected. In the carpal joints similar subchondral cysts, sometimes associated with joint space narrowing, were found much more frequently in the group with CC. There was no direct relation with the presence of calcification.

Chondrocalcinosis (CC) is characterised by deposition of calcium pyrophosphate dihydrate in joint tissues. Although CC might be familial, or associated with a variety of diseases such as hyperparathyroidism or haemochromatosis, it is most common in elderly people without any detectable metabolic abnormality. ${ }^{12}$ A destructive arthropathy has been described in patients with $\mathrm{CC}^{3-5}$ in whom it is more frequent than in a control population with generalised osteoarthrosis (GOA) ${ }^{67}$ Other particular features of $\mathrm{CC}$ include radiological lesions compatible with osteoarthrosis but situated at unusual sites. ${ }^{18}$ In addition several authors have been impressed by a particular radiological expression of osteoarthrosis of the joints of the hands in patients with CC. The most typical features were subchondral cysts in the bones of the metacarpophalangeal (MCP) and carpal joints, sometimes associated with joint space narrowing and osteophytosis. Surrounding osteoarthritic lesions were often minimal. ${ }^{3-5}$ 8-10

Bensasson et al. ${ }^{10}$ and Resnick et al. ${ }^{8}$ and others ${ }^{11} 12$ compared the $x$-ray findings in patients with $\mathrm{CC}$ with those of matched controls without a rheumatological problem and found an increase of osteoarthrotic lesions of carpal and MCP joints in patients with CC. To assess the specificity of a possible arthropathy of the hands in patients with chondrocalcinosis, we decided to compare the $x$-rays of the hands of subsequent patients with GOA and $\mathrm{CC}$ with the $x$-rays of

Accepted for publication 3 December 1982.

Correspondence to Dr T. L. Vischer, Hôpital Cantonal, CH-1211 Genève 4, Switzerland.
46 subsequent patients with GOA alone, matched for age and sex with the first group. Patients of both groups consulted us with osteoarticular symptoms. The results indicate that in CC there seem to be particular arthropathies of the carpal and MCP joints.

\section{Patients and methods}

Two groups of patients were studied. The first group consisted of 46 patients, representing all patients with CC and GOA seen in this Division of Rheumatology between 1978 and 1980. A comparable group of control patients with GOA but not CC were selected from patients, both hospitalised and from the clinics, subsequently consulting physicians from the division of rheumatology for articular pain. The characteristics of both groups are shown in Table 1. All patients in this study had roentgenographs taken with conventional techniques, including the hands, anterior/posterior view (AP); the knees, AP views; the pelvis and shoulders, AP views. By means of the history, clinical examination, and routine biological tests, patients with rheumatoid arthritis, gout, Sudeck's dystrophy, secondary osteoarthrosis, hyperparathyroidism, haemochromatosis, haemosiderosis, etc., were excluded from the study.

The diagnosis of GOA was made when on the radiographs 6 joints or groups of small joints showed evidence of degenerative joint disease such as narrowing of the joint space, sclerotic changes of the adjacent bone, and presence of osteophytes. These 
Table 1 Characteristics of the patients

\begin{tabular}{llll}
\hline & $\begin{array}{l}\text { Number } \\
\text { of } \\
\text { patients }\end{array}$ & $\begin{array}{l}\text { Age } \\
\text { (years) }\end{array}$ & Sex \\
\hline $\begin{array}{l}\text { Generalised } \\
\text { osteoarthrosis }\end{array}$ & 46 & $\begin{array}{l}\text { Median: 79 } \\
\text { Mean: 76.8 } \\
\text { Range: 55-95 }\end{array}$ & $\begin{array}{c}38 \mathrm{~F} \\
8 \mathrm{M}\end{array}$ \\
$\begin{array}{l}\text { Generalised } \\
\text { osteoarthrosis } \\
\text { and } \\
\text { chondrocalcinosis }\end{array}$ & 46 & $\begin{array}{l}\text { Median: 77 } \\
\text { Mean 76.5 }\end{array}$ & $33 \mathrm{~F}$ \\
\hline
\end{tabular}

Table 2 Osteoarthrosis of the interphalangeal joints of the second to fifth fingers

\begin{tabular}{|c|c|c|c|}
\hline \multirow{2}{*}{$\begin{array}{l}\text { No of joints with } \\
\text { severe osteoarthrosis } \\
\text { (grades } 3 \text { and } 4 \text { ) }\end{array}$} & \multicolumn{3}{|c|}{ General osteoarthrosis* } \\
\hline & Alone & $\begin{array}{l}\text { With } \\
\text { chondro- } \\
\text { calcinosis }\end{array}$ & $p$ \\
\hline $\begin{array}{l}\text { Distal } \\
\text { interphalangeal joints } \\
\text { Proximal }\end{array}$ & 100 & 78 & NS \\
\hline interphalangeal joints & 89 & 55 & $\leqslant 0.02$ \\
\hline
\end{tabular}

*Forty-six patients with 368 joints in each group.

criteria are essentially those of Kellgren and Lawrence. ${ }^{13}$ The diagnosis of $\mathrm{CC}$ was made when radiological linear shadows of calcific density within hyaline or fibrocartilage were found in at least 2 joints and/or when typical, positively birefringent crystals were found in synovial fluid on at least at 2 occasions. From the 46 patients with CC 21 had both calcifications on radiographs and crystals in the fluid, whereas the others had only one of the two.

The radiographs of the hands were evaluated by 2 observers (M.B. and T.L.V.) during several sessions. The randomly chosen $x$-rays of 22 patients were examined at the beginning of the evaluation and again at the end. The results of these 2 evaluations did not differ significantly from each other. The radiographs were coded; however, the evaluation was not completely blind, as the typical calcifications sometimes made the diagnosis of CC obvious.

The radiographs were evaluated in the following way: osteoarthrosis of the interphalangeal joints, and the first MCP joint, and the joint between the navicular and the trapezium were graded according to Kellgren and Lawrence ${ }^{13}$ from $0-4$. For second to fifth MCP joints the presence or absence of (1) subchondral cysts, (2) joint space narrowing, (3) deviation of the joint axis, and (4) osteophytosis were noted. For the carpal and wrist joints only joint space narrowing and cystic changes were noted. Calcific deposits were noted according to localisation and form.

Statistical evaluation was by the chi-square test with Yates's correction.

\section{Results}

Osteoarthrosis of both the proximal and distal interphalangeal joints of the second to fifth fingers was rather more frequent and severe in the group with GOA alone (Table 2). Its appearance did not differ in the group with CC. This confirms our previous report on other groups of patients. ${ }^{7}$ Osteoarticular changes were less frequent in the MCP joints. When osteoarthrosis was graded after Kellgren and Lawrence, ${ }^{13}$ no difference was found between the 2 groups of patients. However, in the patients with $\mathrm{CC}$ a particular arthropathy was seen, mainly in the second and/or third MCP joints (Figs. 1, 2). As generally observed, subchondral rarefactions were most obvious, and they were often associated with malalignment, joint space narrowing, and osteophytosis.

As can be seen in Table 3, joints with subchondral cysts or with axis deviation were significantly more frequent in the $\mathrm{CC}$ group. If the 4 signs were taken

Table 3 Arthropathy of the metacarpophalangeal joints (without the thumb)

\begin{tabular}{|c|c|c|c|}
\hline \multirow[t]{2}{*}{ Number of joints with } & \multicolumn{3}{|c|}{ Generalised osteoarthrosis* } \\
\hline & Alone & With chondrocalinosis & $p$ \\
\hline $\begin{array}{l}\text { (1) Subchondral rarefactions } \\
\text { (2) With axis deviation } \\
\text { (3) Joint space narrowing } \\
\text { (4) Osteophytosis } \\
\text { With all } 4 \text { signs }\end{array}$ & $\begin{array}{r}6 \\
16 \\
17 \\
41 \\
4\end{array}$ & $\begin{array}{l}26 \\
34 \\
28 \\
29 \\
17\end{array}$ & $\begin{array}{l}\leqslant \cdot 001 \\
\leqslant 0 \cdot 02 \\
\text { NS } \\
\text { NS } \\
\leqslant 0.01\end{array}$ \\
\hline $\begin{array}{l}\text { Number of hands with at least } \\
\text { one joint with all } 4 \text { signs }\end{array}$ & 2 & 11 & $\leqslant 0.02$ \\
\hline
\end{tabular}

*Forty-six patients with 92 hands in each group. 


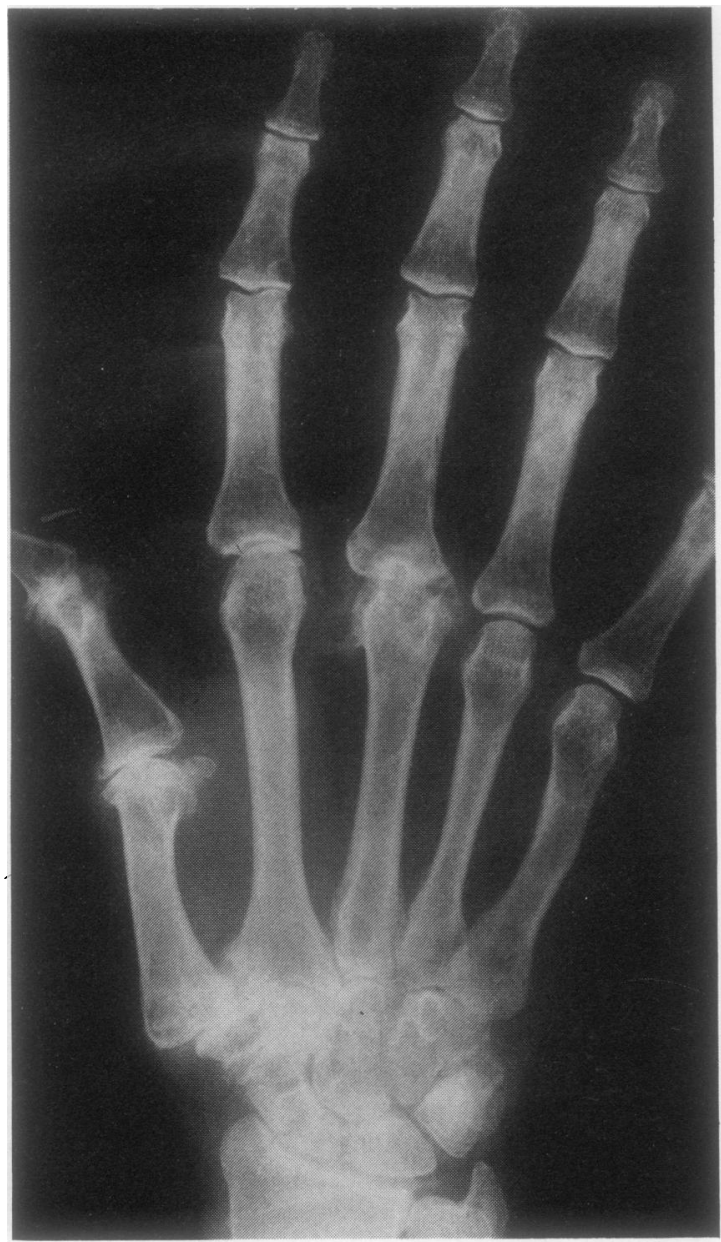

Fig. 1 Hand with pyrophosphate arthropathy. There are subchondral rarefactions of variable size and form in the head of third metacarpal and the carpal bones. Subluxation of the third proximal phalange. Relatively exuberant osteophytosis and free ossicles in the third metacarpophalangeal joint. In the second metacarpophalangeal joint there is some localised joint space narrowing. Arthrosis of the joints between the first metacarpal and trapezium and between the latter bone and the navicular. Calcification of the ligamentum triangulare. together, the hands of patients with $\mathrm{CC}$ were much more often affected. One to 2 joints only, usually the second and third MCP, were involved. Deviation of the joint axis was usually slight and occurred in both lateral and forward directions. In the latter case it had to be distinguished from slight flexion deformities. The subchondral rarefactions had different aspects and were more frequently seen in the distal parts of the metacarpal bone than in the phalanges. The cysts were of different size, often with irregular margins. Sclerosis was not always present. The bone was generally well mineralised. Osteophytes were often exuberant. There was less sclerosis of the subchondral bone than is usually seen in ordinary osteoarthrosis. Joint space narrowing might be present in isolation. Sometimes it was accompanied by an irregular abrasion of the surface. In CC calcifications were often seen round the MCP joints. Often they were not limited to the joint cartilage. But the arthropathy had no direct relation to the radiographically visible calcifications, and could occur in their absence.

The wrist and the carpal joints also seemed to be the site of an arthropathy related to chondrocalcinosis. The most typical findings in the wrists were again localised subchondral rarefactions. These were sometimes associated with joint space narrowing, but not necessarily so (Table 4). Erosive changes similar in appearance to those in the MCP joints were occasionally seen in $\mathrm{CC}$ hands. The subchondral rarefactions had a similar form to those seen in the distal metacarpal heads (Fig. 3).

Bensasson et al. ${ }^{10}$ had found an increase in the frequency of arthrosis of the joint between the trapezium and the scaphoid in their group of CC patients as compared with non-rheumatological controls, whereas the usual arthrosis between the first metacarpal bone and the trapezium was no more frequent. We could not find this same difference between the 2 groups.

\section{Discussion}

The arthropathy of the MCP and carpal joints in patients with CC that we describe has some characteristic features. The subchondral rarefactions in

Table 4 Arthropathy of the carpal joints (subchondral rarefactions with or without localised joint space narrowing)

\begin{tabular}{lcccc}
\hline & \multicolumn{2}{l}{ Generalised osteoarthrosis* } & $p$ \\
\cline { 2 - 4 } & Alone & With chondrocalinosis & 0.001 \\
\hline Number of patients with arthropathy & 8 & 26 & 0.001 \\
Number of hands with arthropathy & 11 & 42 & 0.001 \\
with joint space narrowing & 8 & 28 & 0.02 \\
without joint space narrowing & 3 & 14 & \\
\hline
\end{tabular}

*Forty-six patients with 92 hands in each group. 


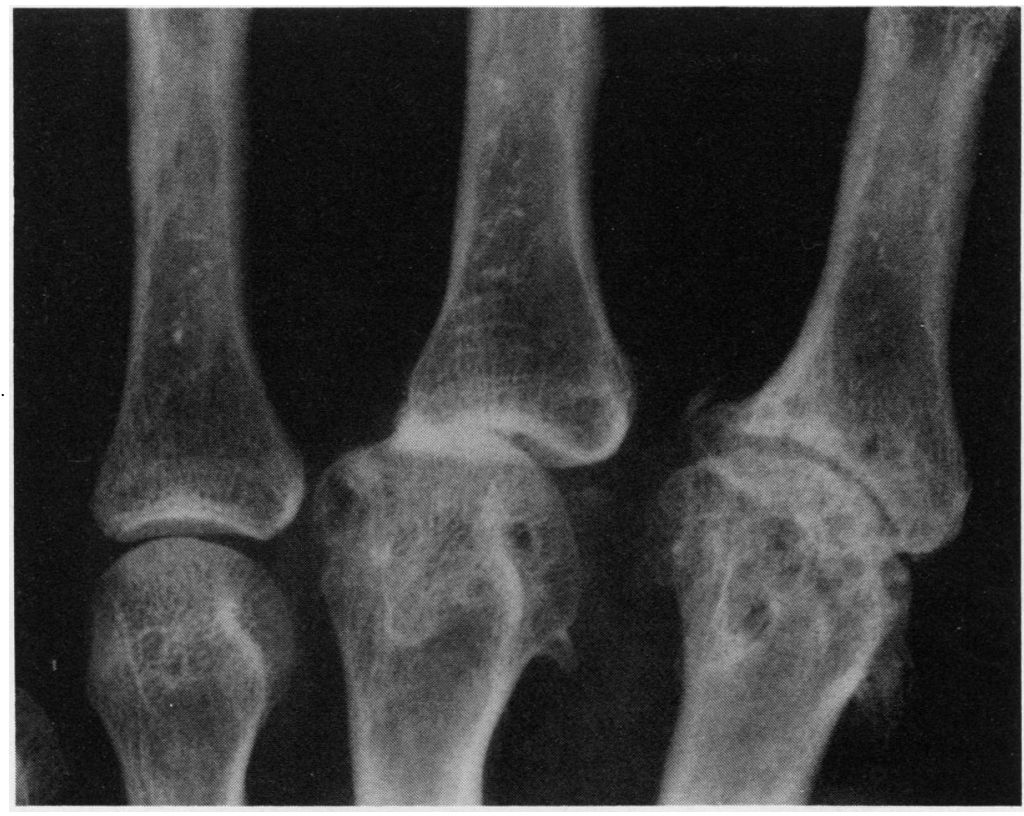

Fig. 2 Close view of the second to fourth metacarpophalangeal $(M C P)$ joints of a patient with $C C$. Exuberant osteophytosis in the second and third MCP joints with joint space narrowing and axis deviation. Extensive irregular, subchondral rarefactions in the bones of the second and third MCP joints. Calcification of the joint cartilage and in the synovium can be seen in the third MCP joint.

Irregular surface of the head of the second metacarpal bone. The third $M C P$ joint does not show any abnormality.

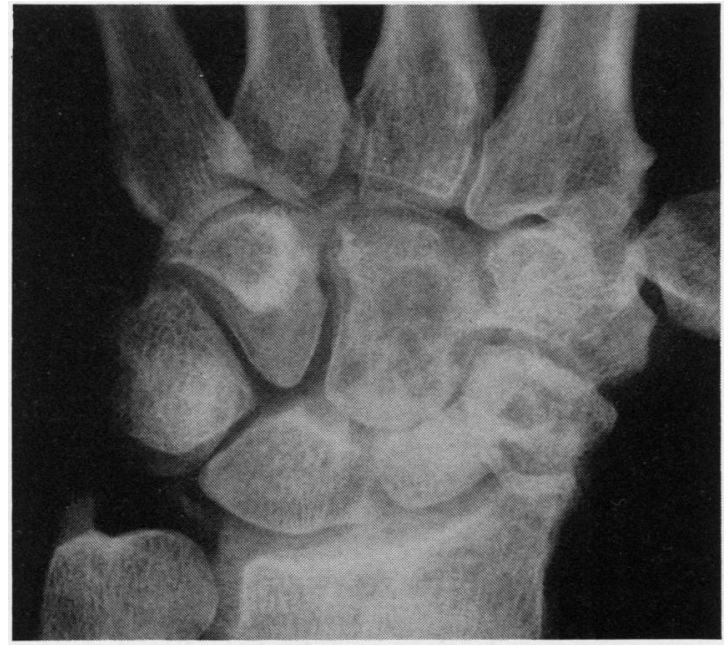

Fig. 3 Wrist from a patient with chondrocalcinosis. Numerous irregular cysts mainly in the os capitatum. Calcification of the ligamentum triangulare. There is little joint space narrowing.

both the carpal bones and the bones of the MCP joints have been previously linked to pyrophosphate arthropathy. ${ }^{3-5810}$ The association of the subchondral rarefactions with joint space narrowing and osteophytosis, which is often exuberant, has also been observed. Deviation of the joint axis seems to be another, less well recognised feature. It can go on to subluxation and seems to be typical for the arthropathy. This arthropathy may lead to bone destruction, as seen also in some of our patients. Destruction begins with diffuse irregularities of the superficial bone. Any one of the signs described above may occur in isolation.

For several reasons we think that the radiologically defined arthropathy described in this paper is relatively specific for $\mathrm{CC}$, though similar lesions have been described in osteoarthrosis ${ }^{13}{ }^{14}$ and have been found in a small number of our patients with GOA only. In osteoarthrosis alone osteophytes are more frequent, as is subchondral sclerosis. Changes in the MCP joints are usually associated with severe changes in the other finger joints, which was not necessarily the case in our patients with CC. Degenerative changes in the carpal joints, if we disregard the first carpometacarpal joint and the joint between the trapezium and the navicular, are relatively rare in the absence of a history of trauma. This has been corroborated in our group with GOA.

The lesions described are also different from those of rheumatoid arthritis, as discussed already by Martel et al. ${ }^{14}$ In CC the lesions are limited to the second and third MCP and carpal joints; the other joints are usually normal and do not show generalised periarticular osteoporosis as typically seen in rheumatoid arthritis. If erosive changes occur in $\mathrm{CC}$, they do not have the characteristics of the marginal erosions found in rheumatoid arthritis but are more diffuse.

Lesions similar to those described here in $\mathrm{CC}$ are a 
recognised feature of haemochromatosis. ${ }^{15-18}$ However, many of the patients with such an arthropathy have signs of $\mathrm{CC}$ as well. It is therefore not clear whether haematochromatosis is the important factor or CC. In our patients we have excluded, by simple tests, most of the diseases which predispose for CC and which could participate in the responsibility for the arthropathy described. Both in our previous study ${ }^{19}$ and in other studies, ${ }^{20}$ cases of secondary CC are rare when $\mathrm{CC}$ in elderly patients is investigated. It seems therefore likely that the pyrophosphate arthropathy of the hands described here is in relation to CC rather than to another known metabolic disease.

The pathogenesis of this arthropathy is unclear. Inflammation is closely associated with pyrophosphate arthropathy and might contribute to its pathogenesis. Another underlying metabolic defect might predispose to both calcium pyrophosphate deposition and the arthropathies associated with it. But, as long as the primary disturbances in CC are not established, all explanations remain speculative.

In conclusion, we have completed previous descriptions of a particular arthropathy of the MCP and carpal joints and shown its specificity by comparing a group of rheumatological patients with $\mathrm{CC}$ with another group with a similar degree of generalised osteoarthrosis. This arthropathy can be differentiated from osteoarthrosis and other joint diseases. Perhaps other subgroups of common osteoarthrosis can be separated in the future, permitting more directed aetiological studies in a search for specific treatment for these conditions.

\section{References}

1 McCarty D J. Calcuim pyrophosphate crystal deposition disease: psuedogout; articular chondrocalcinosis. In: McCarty D J, ed. Arthritis and allied conditions. 9th ed. Philadelphia: Lea and Febiger, 1979: 1276-99.

2 Delauche M-C, Stehle B, Cassou B, Verret J-M, Kahn M-F. Fréquence de la chondrocalcinose radiologique après 80 ans. Une étude prospective. Rev Rhum Mal Osteoartic 1977; 44: 555-7.

3 Martel W, Champion C K, Thompson G R, Carter T L. A roentgenologically distinctive arthropathy in some patients with the pseudogout syndrome. J Roentgenol 1970; 109: 587-605.
4 Menkes C-J, Simon F, Chouraki M, Ecoffet M, Amor B, Delbarre F. Les arthropathies destructrices de la chondrocalcinose. Rev Rhum Mal Osteoartic 1973; 40: 115-23.

5 Richards A J, Hamilton E B D. Destructive arthropathy in chondrocalcinosis articularis. Ann Rheum Dis 1974; 33: 196-203.

6 Gerster J C, Vischer T L, Boussina I, Fallet G H. Joint destruction and chondrocalcinosis in patients with generalized osteoarthrosis. Br Med J 1975; iv: 684.

7 Gerster J C, Vischer T L, Fallet G H. Destructive arthropathy in generalized osteoarthritis with articular chondrocalcinosis. $J$ Rheumatol 1975; 2: 265-9.

8 Resnick D, Niwayama G, Georgen T G, et al. Clinical, radiographic and pathologic abnormalities in calcium pyrophosphate dihydrate deposition disease (CPPD): pseudogout. Radiology 1977; 122: 1-15.

9 Utsinger P D, Zvaifler N J, Resnick D. Calcium pyrophosphate dihydrate deposition disease without chrondrocalcinosis. J Rheumatol 1975; 2: 258-66.

10 Bensasson M, Dorfmann H, Perez-Busquier M, et al. Etude radiographique de la main dans 50 cas de chondrocalcinose articulaire primitive. Comparaison avec une série de 100 témoins. Rev Rhum Mal Osteoartic 1975; 42: 3-11.

11 Megard M, Vignon E, Arlot M, Pont P, Moos S. Etude épidémiologique et clinique de la chondrocalcinose articulaire (C.C.A.) dans une population de 200 vieillards. Rhumatologie 1981; 33: 359-64.

12 Memin Y, Monville Cl, Ryckewaert A. La chondrocalcinose articulaire après 80 ans. Rev Rhum Mal Osteoartic 1978; 45: 77-82.

13 Kellgren J H, Lawrence J S. Radiological assessment of osteoarthrosis. Ann Rheum Dis 1957; 16: 494-502.

14 Martel W, Snarr J W, Horn J R. The metacarpophalangeal joints in interphalangeal osteoarthritis. Radiology 1973; 108: 1-7.

15 Hamilton E, Williams $R$, Barlow $K$ A, Smith $P$ M. The arthropathy of idiopathic haemochromatosis. $Q \mathrm{~J}$ Med 1968; 37: 171-82.

16 Atkins C J, McIvor J, Smith P M, Hamilton E, Williams R. Chondrocalcinosis and arthropathy: studies in haemochromatosis and in idiopathic chondrocalcinosis. $Q J$ Med 1970; 39: 71-82.

17 Hamilton E B D, Bomford A B, Laws J W, Williams R. The natural history of arthritis in idiopathic haemochromatosis: progression of the clinical and radiological features over ten years. $Q J$ Med 1981; 50: 321-9.

18 Gras J-P, Levenez J-P, Raiz A-M, Demangeat P, Gras F. Les arthropathies de l'hémochromatose primitive. Rhumatologie 1980; 32: 57-64.

19 Cosendai A, Gerster J C, Vischer T L, Burckhardt P, Boussina I, Fallet G H. Arthropathies destructrices liées à la chondrocalcinose articulaire: étude clinique et métabolique de 16 cas. Schweiz Med Wochenschr 1976; 106: 8-14.

20 Alexander G M, Dieppe P A, Doherty M, Scott D G I. Pyrophosphate arthropathy: a study of metabolic associations and laboratory data. Ann Rheum Dis 1982; 41: 377-81. 